NASA Technical Memorandum 106234

ALAA-93-1779

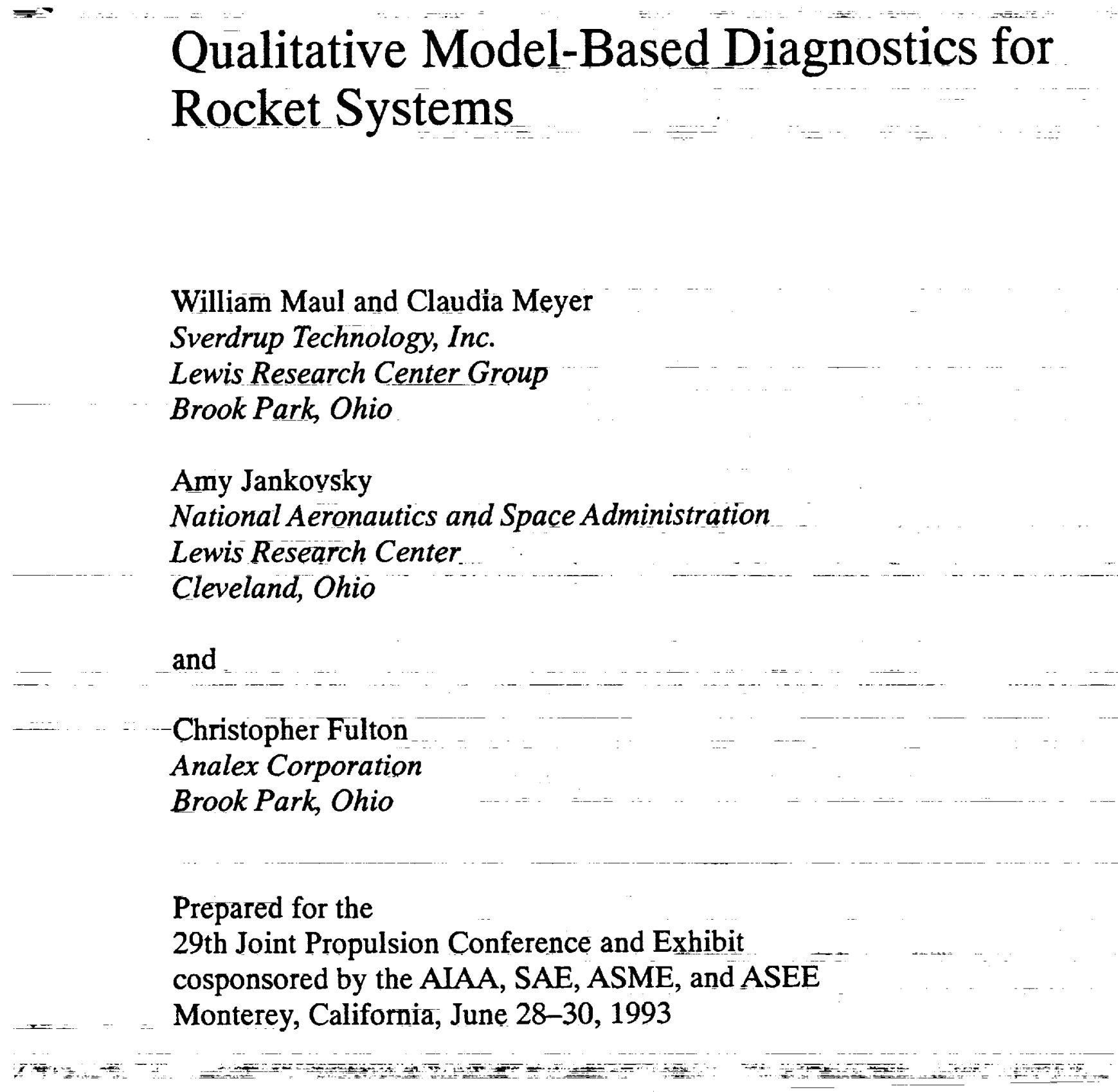

\section{Qualitative Model-Based Diagnostics for Rocket Systems}

William Maul and Claudia Meyer

Sverdrup Technology, Inc.

Lewis Research Center Group

Brook Park, Ohio

Amy Jankoysky

National Aeronautics and Space Administration

Lewis Research Center.

Cleveland, Ohio

and

Christopher Fulton

Analex Corporation

Brook Park, Ohio

Prepared for the

29th Joint Propulsion Conference and Exhibit

cosponsored by the AIAA, SAE, ASME, and ASEE

Monterey, California, June 28-30, 1993 


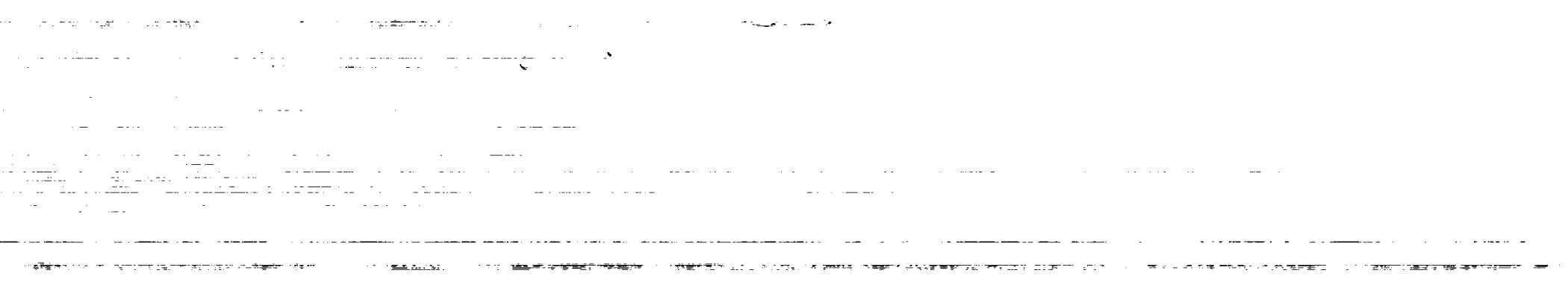

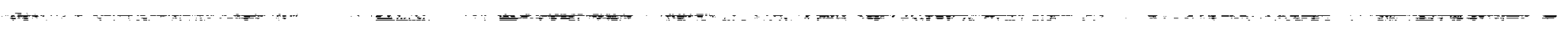

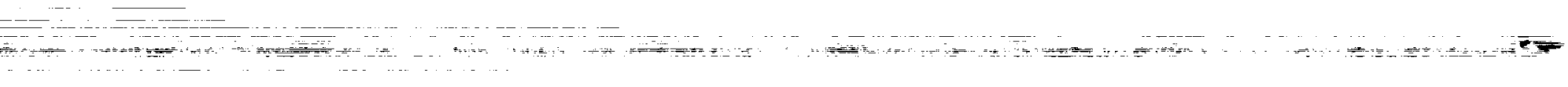

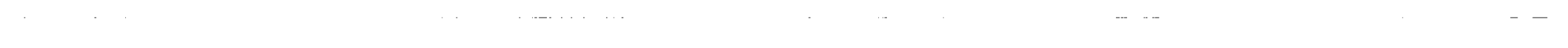

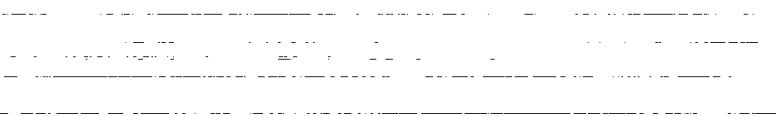
$\ldots$
$\ldots$ 


\title{
Qualitative Model-Based Diagnostics for Rocket Systems
}

\author{
William Maul and Claudia Meyer \\ Sverdrup Technology, Inc \\ Lewis Research Center Group \\ Brook Park, OH
}

Amy Jankovsky

NASA Lewis Research Center

Cleveland, $\mathrm{OH}$

\author{
Christopher Fulton \\ Analex Comporation \\ Brook Park, OH
}

\begin{abstract}
A diagnostic software package is currently being developed at NASA Lewis Research Center that utilizes qualitative model-based reasoning techniques. These techniques can provide diagnostic information about the operational condition of the modeled rocket engine system or subsystem. The diagnostic package combines a qualitative model solver with a constraint suspension algorithm. The constraint suspension algorithm directs the solver's operation to provide valuable fault isolation information about the modeled system. A qualitative model of the Space Shuttle Main Engine's oxidizer supply components was generated. A diagnostic application based on this qualitative model has been constructed to process four test cases: three numerical simulations and one actual test firing. The diagnostic tool's fault isolation output compared favorably with the input fault condition.
\end{abstract}

\section{Introduction}

This research was conducted to demonstrate the applicability of qualitative model-based reasoning to automated rocket engine diagnosis. An accurate diagnosis is important in order to predict the engine's future operation in the event of an anomaly. For the Space Shuttle Main Engine (SSME), engine operation is assessed from information provided by performance sensors which are sparsely distributed, prone to failure and insensitive to certain failure modes.1,2 Therefore, automated rocket engine diagnosis can be_a difficult process where domain experts base identification on experience and limited engine performance information.

One type of automated diagnostic system, called an expert system, uses a combination of empirically-driven algorithms and heuristic rules to isolate and diagnose fault conditions. Expert systems are capable of providing diagnostic analysis on anticipated or previously observed fault conditions, but lack the comprehensive descriptions of the system's behavior that would enable diagnosis of unanticipated conditions. Diagnostic systems using model-based reasoning techniques can be augmented with expert systems. Model-based reasoning systems use first-principle relations to provide a more complete representation of the modeled system's behavior. Therefore these systems provide a more thorough diagnostic analysis, considering all possible behaviors to the given input intormation.

Model-based reasoning systems can be developed using either numerical or qualitative models. Qualitative models provide an abstract representation of the modeled system's behavior in a symbolic format. The symbolic format enables the application of nonsequential processing techniques. Because qualitative models are less complex than numerical models and do not require sequential solving, a more complete analysis of possible engine behaviors can be provided with less use of computer resources.

Qualitative system-level models can be generated by connecting discrete qualitative component behavior models. This approach allows the system behavior to be defined as the interaction of discrete component models, rather than a single monolithic system model. The model structure parallels the system's physical structure and permits an intuitive analysis of the simulation output, as well as a method for model construction. The model format and solution method developed by Kuipers 3 were selected because they allow for a flexible level of modeling detail. NASA Lewis researchers had previously used Kuipers' approach to develop a small component behavioral model of the SSME interpropellant seal package; multiple seal failures were successfully simulated based on a model developed using information on single seal failures. ${ }^{4}$

In this investigation, the selected qualitative-modeling approach was applied to a larger system, the SSME oxidizer feed system. Qualitative models of components such as ducts, pumps, turbines, valves and combustors were generated and combined into a
Copyright $(1993$ by the American Institute of Aeronautics and Astronautics, Inc. No copyright is asserted in the United States under Title 17, U.S. Code. The U.S. Government has a royalty-free license to exercise all rights under the copyright claimed herein for Governmental purposes. All other rights are reserved by the copyright owner.

.


system model. Automated diagnosis was demonstrated using model-based reasoning techniques applied to the SSME qualitative model. This paper provides a background on qualitative modeling and describes the development of the Qualitative Diagnostic System (QDS), an automated diagnostic system based on qualitative models. Four SSME test cases have been analyzed using the QDS. Each test case represents a unique faut condition within the SSME oxidizer feed system. The QDS processed each test case and the resulting diagnoses were evaluated.

\section{QDS Development}

Figure 1 illustrates the information flow of the QDS. First, the numerical data are preprocessed into symbolic values (e.g. high, nominal, or low). The symbolic values are input to the qualitative model solver. The solver attempts to find a solution of the system model which is consistent with the symbolic input set. The results from the solver are passed through a portion of the QDS containing the constraint suspension algorithm. If a solution consistent with nominal behavior is found, then the system is presumed to be behaving properly and no further diagnostic analysis is required of the QDS. If, however, a consistent solution cannot be determined, then the QDS initiates a process to isolate the area within the engine where the inconsistency is occurring. The process, called constraint suspension, removes various portions of the model and passes the remaining model and input set to the model solver. The QDS continues the constraint suspension until the fault has been identified to the level of detail available from the model. The development of the QDS was divided into three modules: data preprocessing, qualitative model solver and constraint suspension algorithm.

\section{Qualitative Modellng}

A qualitative model is a collection of constraints that symbolically describe the system's behavior. Each constraint is based on a first-principle relationship between parameters. Each parameter has a modelspecific domain that is segmented by landmark values. Landmark values are predefined values that anchor the actual system behavior to the qualitative model ${ }^{3}$ and can be established either statistically or heuristically.

In the component-based methodology, discrete component models are developed separately and then connected together to form a larger system model. This methodology permits component models to be developed at different levels of detail. Discrete component models allow easier modifications and can be maintained in a library for the development of future models. An automated process has been developed which properly connects the discrete component models into a system model. In addition to the development advantages, component-based system models facilitate the implementation of diagnostic assessment techniques used in model-based reasoning.

\section{Data Preprocessing}

The data preprocessing module converts numerical data to symbolic values for input to the qualitative model. Two types of data were supplied to the qualitative model: numerically simulated and actual test data. For the numerically simulated data, difference values for each parameter were calculated between the anomalous simulation and a baseline nominal simulation. For actual test data, the raw numerical data were divided into equal time segments and averaged over each time segment to eliminate sensor noise. Difference values were then generated between parameters' values at the current and previous time slice. The time-averaged values at the previous time slice were used as the nominal baseline values. The difference values were then converted into symbolic representations by comparing them to predefined landmark values.

\section{Qualitative Model Solver}

The qualitative model solver uses constraintsatisfaction propagation techniques developed by Mackworth 4 to provide consistent global solutions of the qualitative model for the given input information. First, the qualitative model solver generates all possible combinations of parameter values for each constraint. Parameter combinations inconsistent with the individual constraints are then eliminated or filtered out. Finally, global solutions are determined by selecting parameter combinations consistent between constraints; this process is referred to as a path consistency filter. 5

Consideration must be given to the implementation of the path consistency filter. Due to limited input information, ambiguous intermediate parameters and the detail of the qualitative model, large models have correspondingly large search spaces which must be processed by the path consistency filter. Thus, the computation times required to obtain all possible solution sets for large models are greatly extended. The ODS model solver used a processing queve, based on how the parameters were linked in the system model and the number of possible values each parameter had, to guide the path consistency filter. This approach greatly reduced the amount of processing time required by the QDS.

\section{Constraint Suspension Algorithm}

The constraint suspension algorithm (CSA) is used to determine potential causes of anomalous input data by 
isolating the failure to some system sublevel.6,7 In a component-based system model as illustrated in figure 2 , constraint suspension may be used for fault isolation at successively increasing levels of depth. At each hierarchical level, the CSA first suspends individual components of the model at that level, and if no consistency is found, it then suspends combinations of components at that level. Each time a component or group of components is determined to contain the anomalous condition, the CSA performs the suspension technique again on constraints or blocks of constraints that represent the subcomponents within that component. This process is continued until no further refinement of component isolation can be made.

Each isolated component model indicates the possibility that the fault condition manifests itself within that particular component. Specific anticipated fault conditions can be represented within each component model as a combination of individual parameters and constraints which, when suspended, would provide a consistent model solution. When an individual parameter (e.g. pump efficiency) indicates a fault condition, then the parameter is called a fault parameter. Initially, fault parameters are set to their nominal values. When a fault parameter is suspended, the parameter is allowed to take on any value within its domain. If specific tault conditions are available within the model, the constraint suspension algorithm will investigate each condition within the isolated components.

\section{Apollcation}

In this study, the oxidizer side of the SSME was selected for qualitative modeling; a schematic of the modeled system, its interfaces to other parts of the engine, and sensor locations is shown in figure 3 . The oxidizer side of the engine supplies liquid oxygen (LOX) to the two preburners, the main combustion chamber and the heat exchanger. The LOX enters the engine through the low pressure oxidizer pump (LPOP). The LPOP is driven by the low pressure oxidizer turbine (LPOT). The LPOP and the LPOT discharge flows are merged since they are both in the liquid phase. This combined flow enters the high pressure oxidizer pump (HPOP). The discharge flow of the HPOP supplies LOX to several engine components, including the main combustion chamber, the LPOT and the preburner boost pump (PBP). The PBP raises the pressure of the LOX supplied to the engine's preburners. The LOX flow to the oxidizer preburner (OPB) is controlled by the oxidizer preburner oxidizer valve (OPOV). The OPB also receives hydrogen from the fuel side of the engine; the hot combustion flow from the preburner is used to drive the high pressure oxidizer turbine (HPOT). The
HPOT drives the HPOP and the PBP. The turbine discharge flow passes through the hot-gas manifold into the main combustion chamber.

The modelled components include the LPOP, the LPOT, the HPOP, the PBP, the HPOT, the OPB and the OPOV, along with the inter-connecting ducts. No attempt has been made. to model the fuel side of the engine. Detailed descriptions of the constraints for the pumps are given in appendix $A$. Constraints were developed in a similar manner for the other system components. A total of 89 constraints was required to model the oxidizer side of the engine. Twelve sensor parameters were used as inputs to the model. The landmark values selected are characteristic of a $1 \%$ change in engine power-level. Turbomachinery efficiencies and fluid resistances in ducts were initially fixed at nominal values. The remaining intermediate nonmeasurable parameters were not initially set, but were determined by the model solver.

The component-based model for this application is represented by the hierarchical structure shown in figure 4. The LPOTP group includes the LPOP, the LPOT and duct1, while the HPOTP group contains four major components: HPOP, PBP, OPB and HPOT, along with duct2, duct3, duct4 and the OPOV. The only specific fault parameters available within the model are the efficiencies for the individual pumps and turbines, and the fluid resistances within the ducts.

Four qualitative test cases were generated for this application; 3 cases were generated from simulation data, and one case was generated from actual test data. Each test case represented a unique fault condition originating in an oxidizer supply component. Three test cases: HPOT efficiency decrease, HPOP efficiency decrease and PBP efficiency decrease; were simulated using the SSME steady-state numerical model. These cases represent a large number of failure modes for the HPOTP which result in an efficiency change. For example, an HPOT efficiency decrease could be a result of increased mechanical friction in the bearing or seals, or an increase in clearance between the rotor blade tips and the casing. Table 1 shows the qualitative inputs for the three test cases. Each input parameter may have one or two symbolic values, depending on where the numerical value is within the region between landmark values. Each region is divided into five subregions. The assignment of symbolic values within a region is illustrated in figure 5 .

The fourth test case, LPOP cavitation, was generated from actual test stand data. For this case, the inlet pressure to the LPOP decreased to the vapor pressure for this pump and cavitation was induced. Cavitation is 
the spontaneous formation of vapor bubbles at the inlet of a liquid pump and can lower the pressure rise across the pump for the same turbopump shaft speed. The data for this test case was extracted near the time where the cavitation was induced.

\section{Results and Discussion}

Figures 6-8 illustrate the constraint suspension results for each of the three simulated test cases. For test case 1 , the HPOT efficiency decrease, several major components of the HPOTP: the HPOP, the HPOT, the OPB and the PBP, were identified as possible sources of the fault condition. When the available fault parameters within each of these components were suspended individually, only one specific fault condition was identified as a possible diagnosis: the HPOT efficiency decrease. The QDS results for test case 2, the PBP efficiency decrease, identified both the HPOP and the PBP as possible faulty components. The QDS further identified the PBP efficiency decrease as a possible fault condition. For test case 3, the HPOP efficiency decrease, the QDS identified the HPOP and the PBP from the HPOTP, and the LPOP and Duct1 from the LPOTP as possible sources of the fault condition. Again when the available fault parameters within each isolated component were suspended, the QDS identified only the HPOP efficiency decrease as a possible fault condition.

The fourth test case represents actual test data of a fault condition, LPOP cavitation. According to post-test documentation, the inlet pressure to the pump was reduced to satisfy a test objective. The inlet pressure reduction induced cavitation in the LPOP at 140 seconds after engine start. The effect of the cavitation was to change the characteristic behavior of the LPOP. The data from the 140 second time interval were qualified relative to the data extracted from the nominal 139 second time interval. The QDS isolated the fault from the qualified data to the LPOP. Because no specific information is available from the model to indicate pump cavitation, the ODS is only capable of resolving the condition to this level.

Table 2 shows the diagnostic results from the ODS for each of the four test cases. For each case, the QDS resolved the diagnosis down to the lowest level of detail available from the model. For test cases $1-3$, the QDS identified the expected input fault as a possible diagnostic solution. The fourth case resulted in the LPOP being isolated as containing the fault condition.

Although the QDS identified in each test case the component containing the fault condition and in test cases 1-3 the expected fault condition, the QDS was unable to resolve the diagnostic output to a single possibility. The diagnostic results for test case 1 , for example, identify four components as potentially faulty, including the HPOT. The results further identify the HPOT efficiency decrease as a possible fault condition, but there may be other unmodelled fault conditions within the HPOT that are represented by the input. While the diagnostic results are ambiguous, they represent a thorough analysis of the system's actual behavior with respect to the qualitatively-modelled nominal behavior.

There are four causes for the ambiguity within the diagnostic results. Each cause contributes to the ambiguity to some degree and must be addressed, not only to provide a more concise set of diagnostic results, but to limit the amount of computer time required to process the diagnostic model. The causes are the level of detail of the qualitative model, the processing of interval intormation by the QDS solver, the numerical-tosymbolic input information conversion and the available sensor set from the engine.

The first two causes, the detail level of the qualitative model and the interval information processing by the QDS solver, are related to the format of the qualitative model and the process by which this model is solved. By definition, the qualitative model is a simplification of the modeled system. Oversimplification of the parameter relationships could result in lost information which if retained would provide more resolution to the ambiguous results. Additional model detail could provide some resolution to the current set of diagnostic results. The additional detail could be made by generating stronger constraints within the model (e.g. an equality relationship replacing a proportionality relationship). Interval information processing is the propagation of interval values through qualitative constraints. The effect of interval information propagation on the output ambiguity can be reduced to some degree by providing more model detail, but it is an inherent problem in qualitative reasoning ${ }^{8}$. While allowing parameters to take on a range of possible values, provides a thorough and complete evaluation of all possibilities, it can result in spurious solutions and require large amounts of computer processing time.

The last two causes, the available input sensor data and the conversion of numerical input information into symbolic information, involve linking the actual engine system with the qualitative model. The input sensor data restricts parameters at various locations within the qualitative model to specific symbolic values. More sensor information from appropriate locations within the engine would reduce the amount of ambiguity within the model and thus provide refinement of the diagnostic 
output. The conversion of the sensor input data to proper symbolic representations can also cause ambiguity within the model. Allowing input parameters to be assigned multiple symbolic values to overcome the uncertainty of the sensor information, reduces the restriction placed on the qualitative model and therelore increases the number of diagnostic solutions from the model.

\section{Cencluding Remarks}

The research presented here demonstrates the capabilities of the automated qualitative diagnostic system, ODS. A qualitative model of the SSME oxidizer feed system was developed based on the nominal system responses. The QDS used the qualitative system model to perform automated diagnoses for four fault conditions. To provide diagnostic information, the QDS applied constraint suspension techniques to a hierarchical component-based qualitative model to identify possible faulty components. For each test case, the QDS was able to identify the faulty component as one of the components that could have failed. When the qualitative model detail was sutficient, the ODS provided fault condition information. The detail of the qualitative model, the propagation of interval information, the input sensor suite and the conversion of numerical information into symbolic values, influence the ability of the ODS to distinguish between faulty components and fault conditions.

\section{Acknowledgements}

This work was supported under contract NAS3-25266. The authors would like to thank Mike Binder for his contributions to this research.

\section{Appendix A}

The following qualitative constraints were used to model the behavior of the LPOP, the HPOP and the PBP. A pump converts inlet pressure, temperature and flowrate into discharge temperature, pressure and flowrate based on available torque and shaft speed. Qualitative operations for each constraint are represented by their quantitative mathematical counterpart within a circle, and the equivalence symbol is used to represent qualitative equality.

The pump head relationship defines the pressure change across the pump,

$$
[P 2] \equiv[P 1] \oplus[\mathrm{HOP}],
$$

where $\mathbf{P 1}$ is the pump inlet pressure, $\mathbf{P 2}$ is the pump discharge pressure and HOP in the pump head. The input and discharge temperatures and flowrates are related across the pump by,

$$
[\mathrm{T} 2] \equiv[\mathrm{T} 1]+[\mathrm{DT}]
$$

and

$$
[\mathrm{W} 2] \equiv[\mathrm{W} 1] \text {. }
$$

where DT is the temperature change across the pump. Equation 3 assumes that parasitic flows are negligible across the pump. In addition, pump performance characteristics based on the commonly used affinity laws were developed9,

$$
\begin{aligned}
& {[\phi] \equiv[\mathrm{Wl}] \varnothing[\mathrm{SS}],} \\
& {[\Psi] \equiv[\mathrm{HOP}] \varnothing\left[\mathrm{SS}^{2}\right],}
\end{aligned}
$$

and

$$
[\eta] \equiv[\mathrm{FHP}] \varnothing[\mathrm{HP}],
$$

where $\phi$ is the pump flow coefficient, $\Psi$ is the pump head coefficient, $\eta$ is the pump efficiency and SS is shaft speed. The terms FHP, pump fluid horsepower output, and HP, the horsepower input by the pump drive, are constrained by the following relationships,

$$
[H P] \equiv[T O R] \otimes[S S],
$$

and

$$
[F H P] \equiv[H O P] \otimes[W 1],
$$

where TOR is the torque required by the pump. Empirical performance curves for the SSME pumps indicate that for the operational range under consideration the following relationships apply,

$$
[\eta] \equiv \mathbf{M}^{+}[\phi],
$$

and

$$
[\phi] \equiv \mathbf{M}^{-}[\Psi],
$$

where $M-()$ and $M+()$ is nomenclature taken from Kuipers ${ }^{3}$, indicating monotonically decreasing relationship. Also pump efficiencies inversely effect the discharge temperature of the pump ${ }^{10}$, so

$$
[\eta] \equiv \mathbf{M}^{-}[\mathrm{DT}] .
$$




\section{Beferences}

1. Tulpule, S., Pattem Classification Approach to Rocket Engine Diagnostics, AlAA Paper 892850, July, 1989.

2. Wong, K., Space Shuttle Sensor Assessment, Vitro Corporation, Internal NASA HQ Report, April, 1990.

3. Kuipers, B., Qualitative Simulation, Artificial Intelligence, 1986, Vol 29, pp. 289-338.

4. Binder, M., Maul, W., Meyer, C., and Sovie, A. Rocket Engine Diagnostics Using Qualitative Modeling Techniques, AlAA Paper 92-3164, July 1992.

5. Mackworth, A., Consistency in Networks of Relations, Artificial Intelligence, 1977, Vol. 8, pp. 99-118.
6. Davis, R., Diagnostic Reasoning Based on Structural Behavior, Qualitative Reasoning About Physical Systems ed. Bobrow, D., The MIT Press, Cambridge, Mass., 1985, pp. 347410.

7. Reiter, R. A Theory of Diagnosis from First Principles, Artificial Intelligence, 1987, Vol 32. p. 57-95.

8. Struss, P., Problems of Interval-Based Qualitative Reasoning, Beadinos in Qualitative Reasoning About Physical Systems, ed. Weld, D. S. and de Kleer, J., Morgan Kaufmann Publishers, San Mateo, Call., 1990, pp. 288305.

9. White, F. M., Eluid Mechanics McGraw-Hill Book, Now York, 1979.

10. Huzel, D. K. and Huang, D. H., Design of Liquid Propellant Rocket Engines, NASA SP-125, 1967.

Table 1. Model input parameters values used for the numerically simulated test cases and based on the relative change from the baseline simulation.

\begin{tabular}{|c|c|c|c|c|c|c|c|}
\hline \multirow{2}{*}{ Input Parameter } & \multirow{2}{*}{$\begin{array}{c}\text { Change Due } \\
\text { to } 1 \% \\
\text { Power-Level } \\
\text { Change }\end{array}$} & \multicolumn{2}{|c|}{$\begin{array}{l}\text { HPOT Efficiency } \\
\text { Decrease }\end{array}$} & \multicolumn{2}{|c|}{$\begin{array}{c}\text { PBP Efficiency } \\
\text { Decrease }\end{array}$} & \multicolumn{2}{|c|}{$\begin{array}{c}\text { HPOP EHficiency } \\
\text { Decrease }\end{array}$} \\
\hline & & $\begin{array}{l}\text { Numerical } \\
\text { Value }\end{array}$ & \begin{tabular}{|c|}
$\begin{array}{c}\text { Oualitative } \\
\text { Value }\end{array}$ \\
\end{tabular} & $\begin{array}{c}\text { Numerical } \\
\text { Value }\end{array}$ & $\begin{array}{c}\text { Oualiative } \\
\text { Value }\end{array}$ & $\begin{array}{c}\text { Numerical } \\
\text { Value }\end{array}$ & $\begin{array}{l}\text { Qualitative } \\
\text { Value }\end{array}$ \\
\hline $\begin{array}{l}\text { LPOP Inlel } \\
\text { Pressure (psi) }\end{array}$ & 0.0 & 0.0 & nom & 0.0 & nom & 0.0 & nom \\
\hline $\begin{array}{l}\text { LPOP Inlet } \\
\text { Temperature ( }\end{array}$ & 0.0 & 0.0 & nom & 0.0 & nom & 0.0 & nom \\
\hline $\begin{array}{l}\text { LPOP Inlet } \\
\text { Flowrate (GPM). }\end{array}$ & \pm 56.0 & 0.0 & nom & -0.1 & nom & 0.0 & nom \\
\hline $\begin{array}{l}\text { LPOTP Shaft } \\
\text { Spoed (RPM) }\end{array}$ & \pm 30.0 & -2.3 & $\mathrm{~N}$, nom & -0.96 & nom & +5.3 & nom, nh \\
\hline $\begin{array}{l}\text { HPOP Inlet } \\
\text { Pressure (psi) }\end{array}$ & \pm 1.5 & -0.4 & nl, nom & -0.15 & nom & +12 & nh, high \\
\hline $\begin{array}{l}\text { HPOP Discharge } \\
\text { Pressure (psi) }\end{array}$ & \pm 50.0 & -3.3 & ni, nom & -1.08 & nom & +2.1 & nom, nh \\
\hline $\begin{array}{l}\text { PBP Discharge } \\
\text { Pressure (psi) } \\
\end{array}$ & \pm 85.0 & -24.3 & nl, nom & -7.61 & ni, nom & -34.4 & $\mathbf{n}$ \\
\hline $\begin{array}{l}\text { PBP Discharge } \\
\text { Temperalure }\left({ }^{\circ} \mathrm{R}\right)\end{array}$ & \pm 1.0 & -0.2 & nom & +7.23 & ind & +2.5 & inf \\
\hline $\begin{array}{l}\text { OPOV Position } \\
\text { (\% open) }\end{array}$ & \pm 0.004 & +0.029 & in & +0.011 & ind & +0.031 & ind \\
\hline $\begin{array}{l}\text { OPB Chamber } \\
\text { Pressure (psi) }\end{array}$ & \pm 67.0 & +61.5 & nh, high & +20.2 & nom, nh & +61.2 & nh, high \\
\hline $\begin{array}{l}\text { HPOT Discharge } \\
\text { Temperature ( }{ }^{\circ} \text { ) }\end{array}$ & \pm 9.5 & +121.8 & int & +36.8 & int & +115.1 & ind \\
\hline $\begin{array}{l}\text { HPOTP Shaft } \\
\text { Speed (RPM) }\end{array}$ & \pm 225.0 & -6.4 & nom & -2.4 & nom & +12.8 & nom, nh \\
\hline
\end{tabular}

Key: $\quad$ nom $=x$ nominal landmark value $\begin{array}{ll}\text { high } & ==\text { high landmark value in }=\text { interv } \\ n & ==\text { interval between nominal and bw landmark values }\end{array}$ $\mathrm{nh}==$ interval between nominal and high landmark values 
Table 2. Diagnostic results for the four test cases.

\begin{tabular}{|c|c|c|c|}
\hline Case \# & Fault Description & $\begin{array}{l}\text { Isolated } \\
\text { Component }\end{array}$ & Specific Fault \\
\hline 1 & $\begin{array}{l}\text { HPOT efficiency } \\
\text { decrease }\end{array}$ & $\begin{array}{l}\text { HPOP } \\
\text { HPOT } \\
\text { PBP } \\
\text { OPB }\end{array}$ & HPOT efficiency decrease \\
\hline 2 & $\begin{array}{l}\text { PBP efficiency } \\
\text { decrease }\end{array}$ & $\begin{array}{l}\text { HPOP } \\
\text { PBP }\end{array}$ & PBP efficiency decrease \\
\hline 3 & $\begin{array}{l}\text { HPOP efficiency } \\
\text { decrease }\end{array}$ & $\begin{array}{l}\text { LPOP } \\
\text { DUCT1 } \\
\text { HPOP } \\
\text { PBP }\end{array}$ & HPOP efficiency decrease \\
\hline $4^{*}$ & $\begin{array}{l}\text { LPOP pump } \\
\text { cavitation }\end{array}$ & LPOP & None \\
\hline
\end{tabular}

- Actual test data

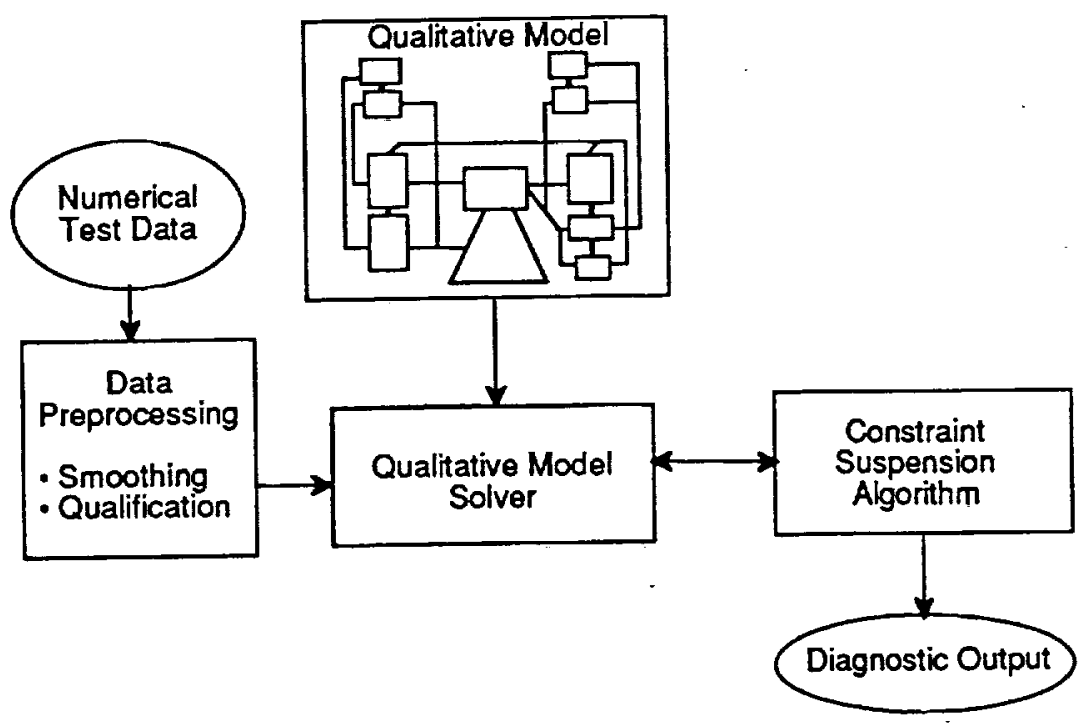

Figure 1. QDS information flow. 


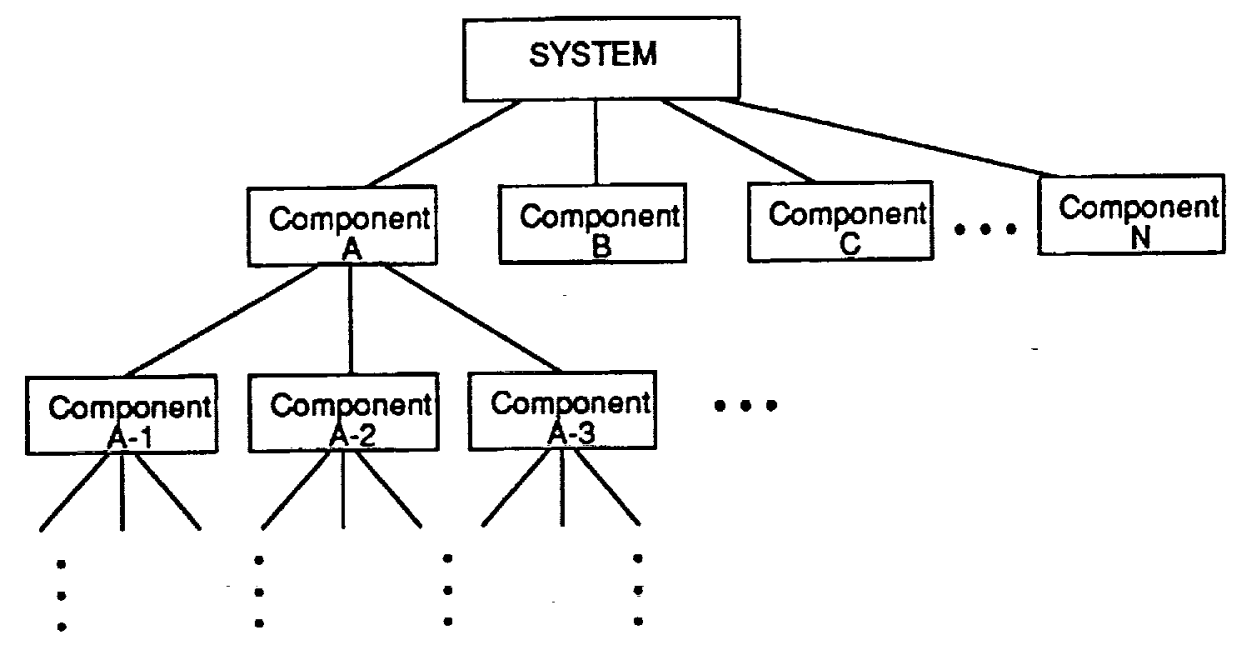

Figure 2. Hierarchical structure of a component-based system model.

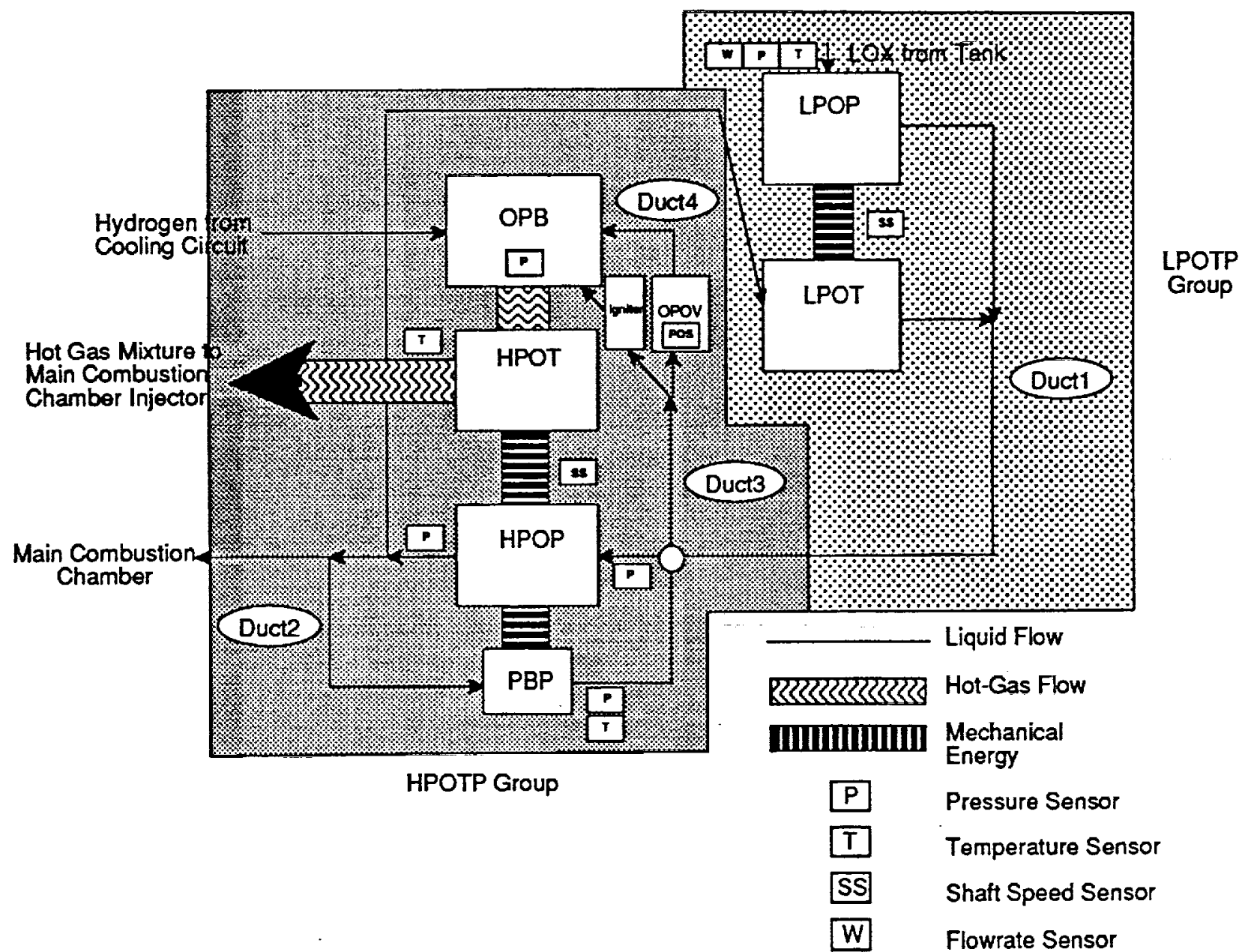

Figure 3. Schematic of the liquid oxygen supply components. 


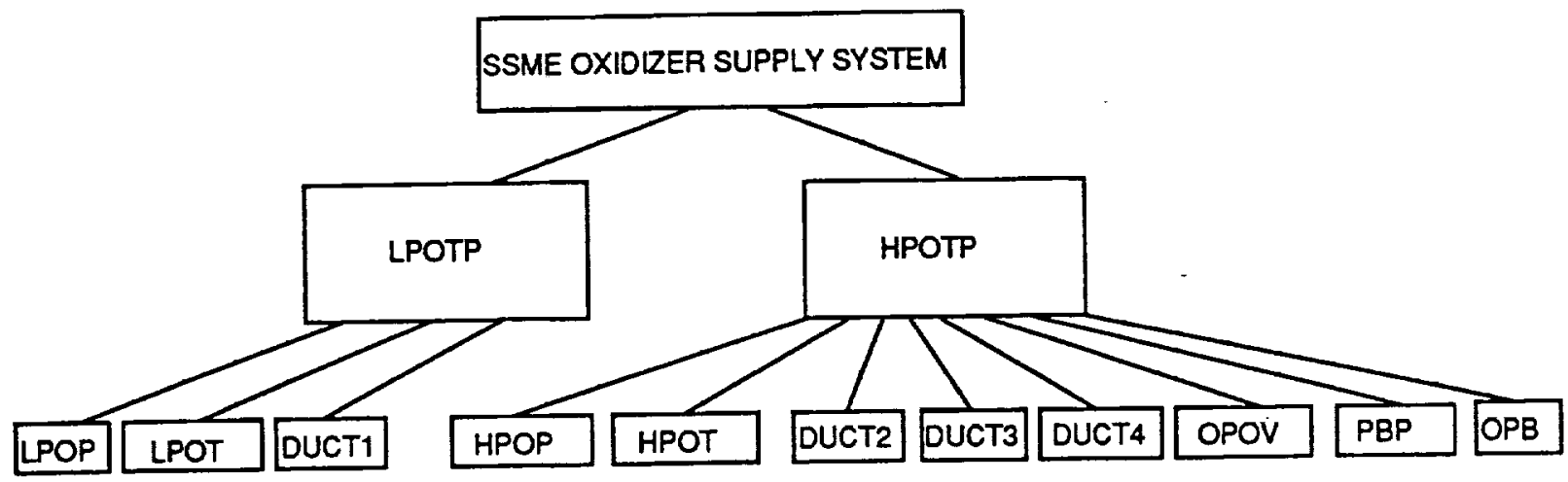

Figure 4. Hierarchical structure for the component-based qualitative model of the SSME oxidizer supply components.

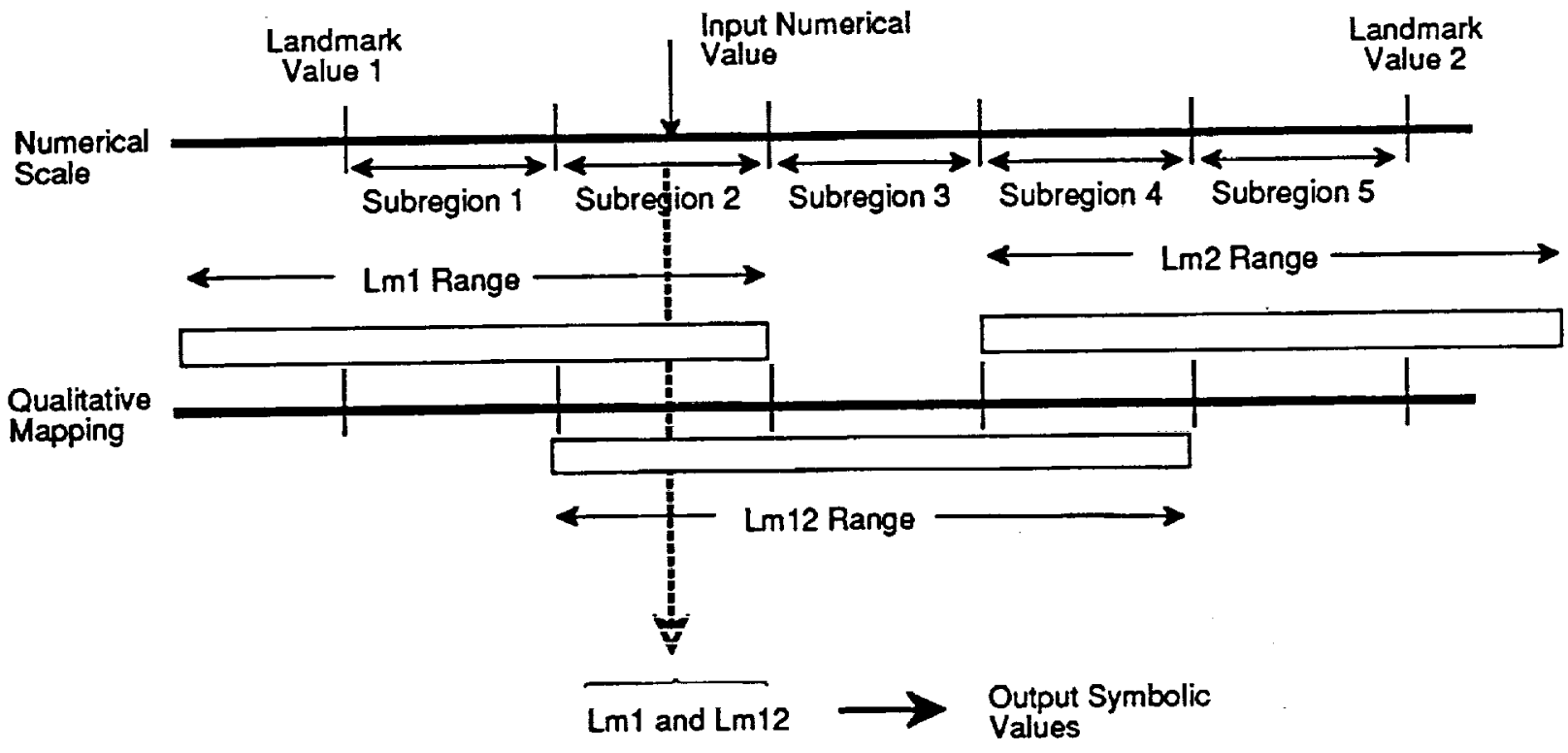

Key: $\mathrm{Lm1}==$ Symbolic value for landmark value 1

Lm2 $=$ = Symbolic value for landmark value 2

Lm12 =x Symbolic value for interval between landmark values 1 and 2

Figure 5. Breakdown of a parameter's domain for qualitative value assignment. 


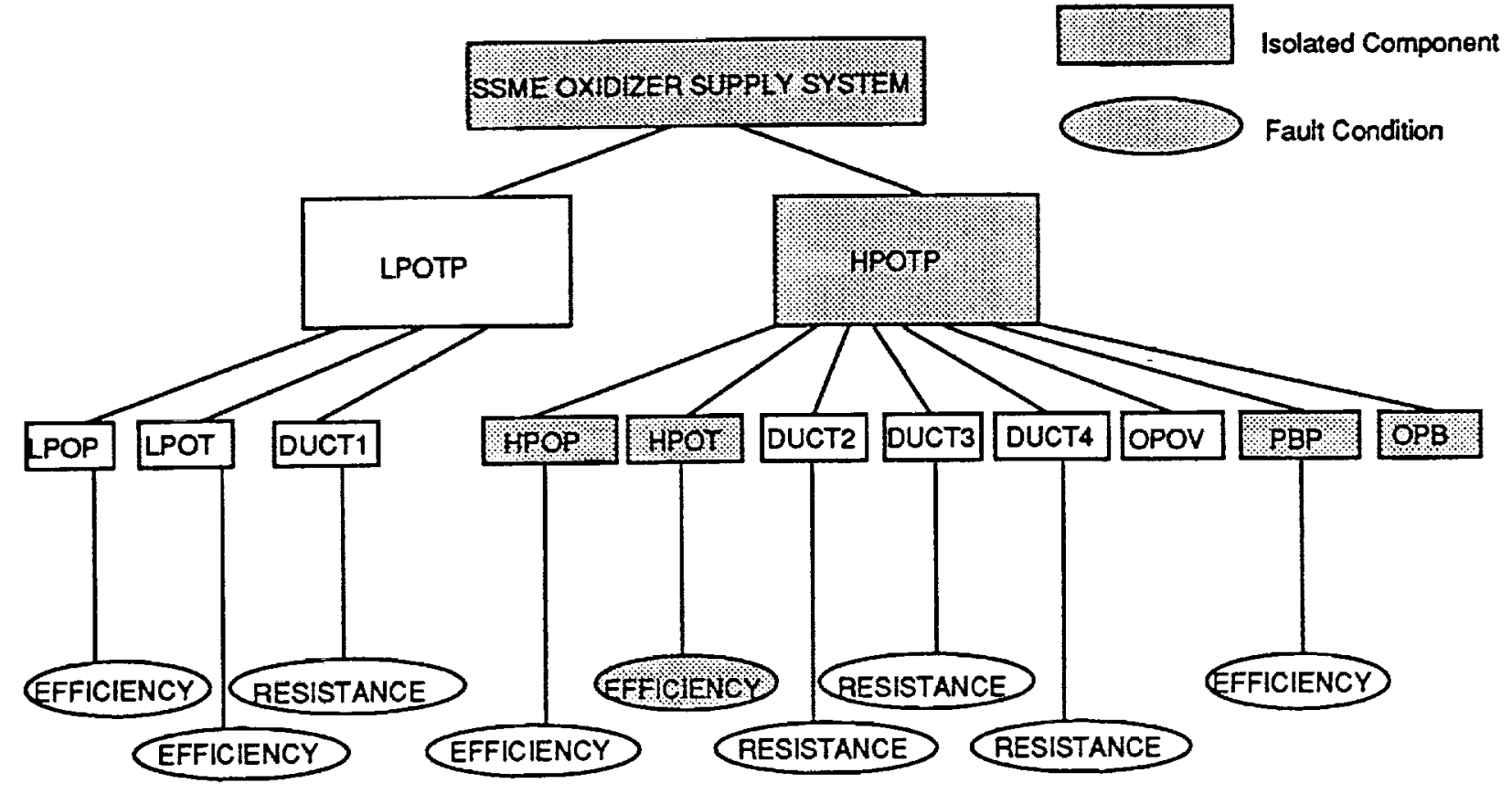

Figure 6. Tree representation of constraint suspension results for case 1, HPOT efficiency decrease.

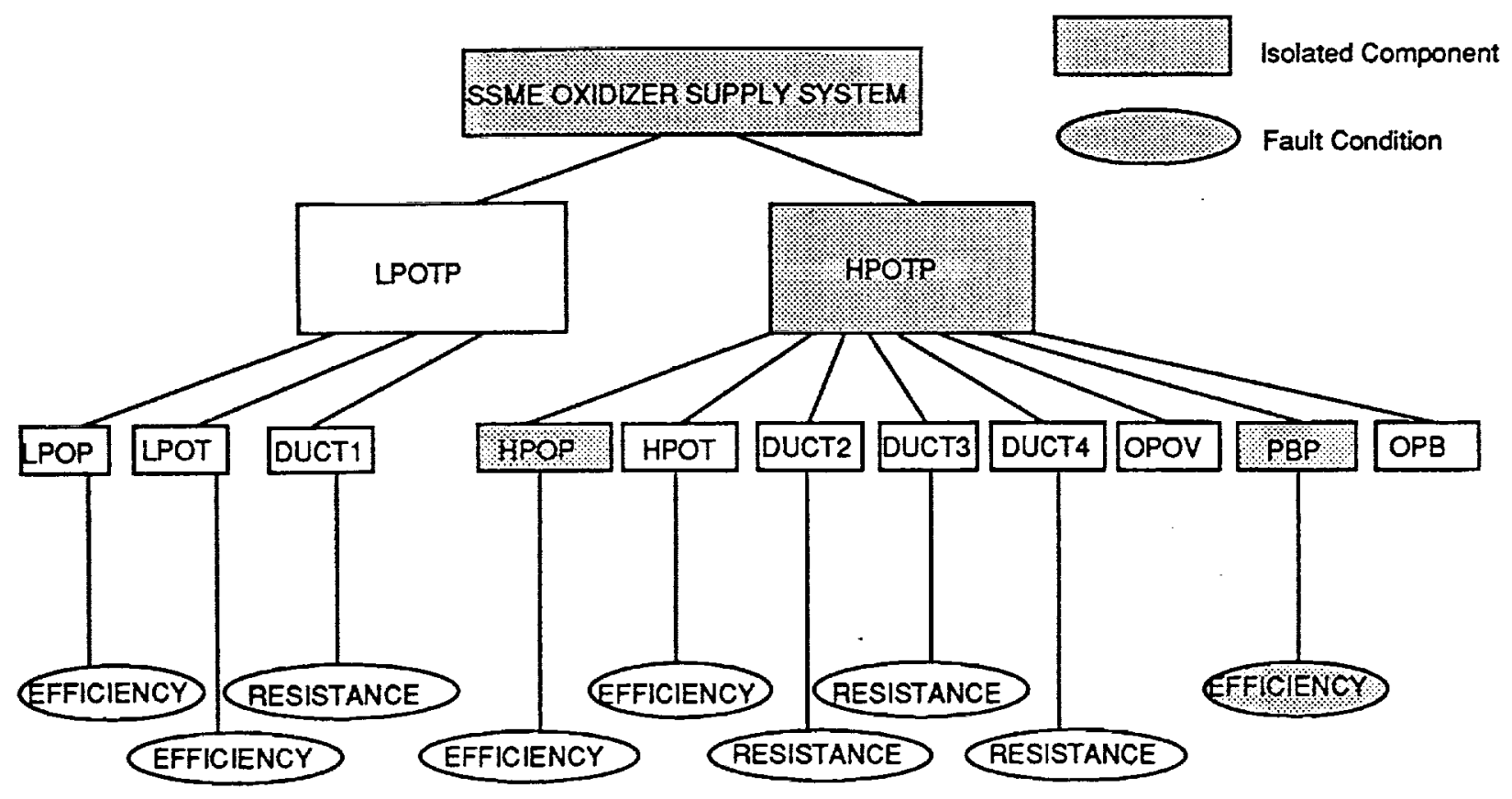

Figure 7. Tree representation of constraint suspension results for case 2, PBP efficiency decrease. 


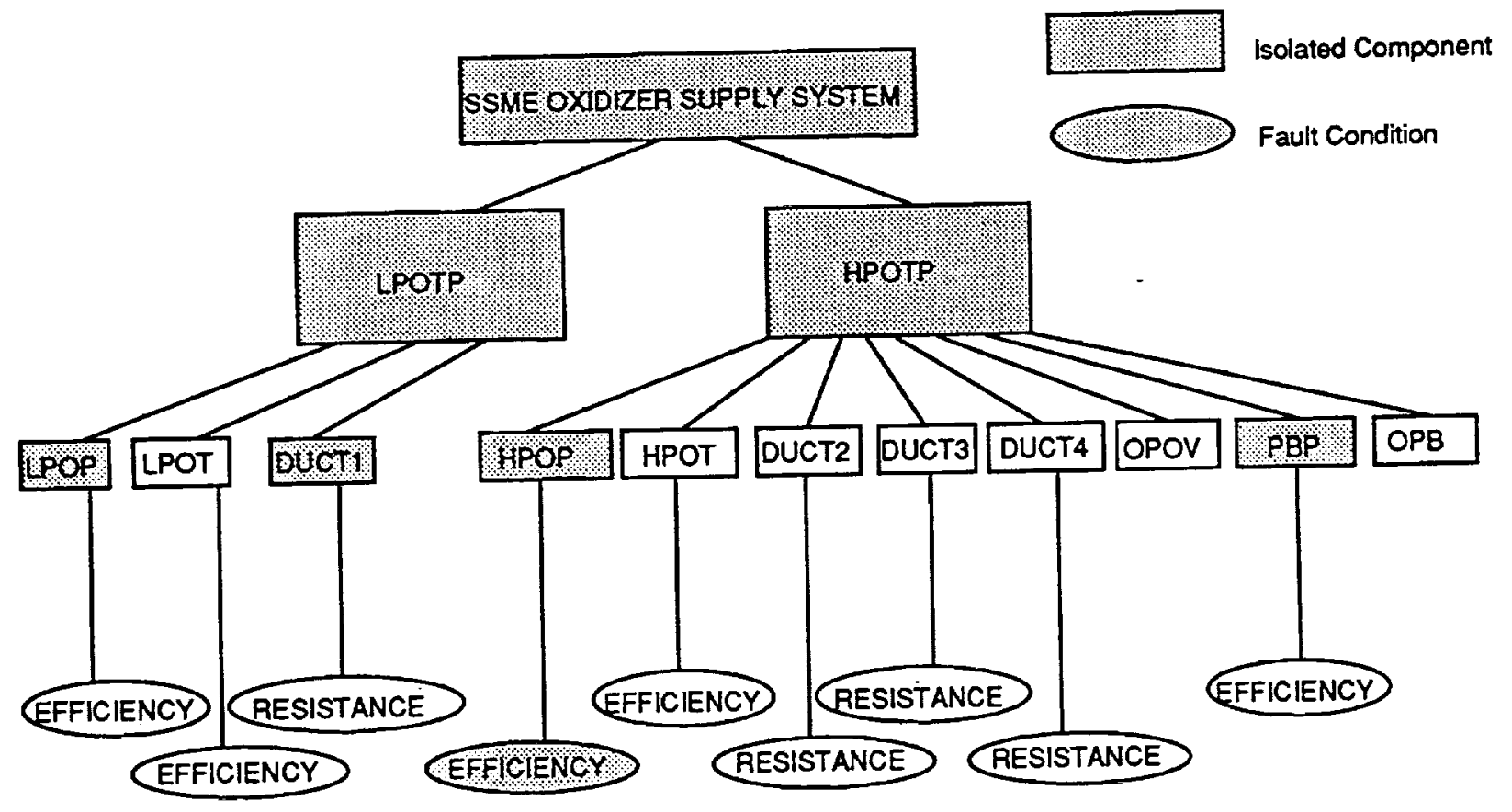

Figure 8. Tree representation of constraint suspension results for case 3, HPOP efficiency decrease. 
Public reporting burden for this collection of information is estimated to average 1 hour per response, including the time for reviewing instructions, searching existing data sources, gatherin and maintaining the data needed, and completing and reviewing the collection of information. Send comments regarding this burden estimate or any other aspect of this collotion of information including sugestions for reducing this burden, to Washington Headquarters Services, Directorate for Information Operations and Reports, 1215 Jefferson Davis Higtway, Suite 1204, Arfington, VA 22202-4302, and to the Office of Management and Budget, Paperwork Reduction Project (0704-0188), Washington, DC 20503.

\begin{tabular}{|l|c|c|}
\hline 1. AGENCY USE ONLY (Leave blank) & $\begin{array}{c}\text { 2. REPORT DATE } \\
\text { June } 1993\end{array}$ & $\begin{array}{r}\text { 3. AEPORT TYPE AND DATES COVERED } \\
\text { Technical Memorandum }\end{array}$
\end{tabular}

\section{TILE AND SUBTITLE}

Qualitative Model-Based Diagnostics for Rocket Systems
5. FUNDING NUMBERS

WU-584-03-11

\section{AUTHOR(S)}

William Maul, Claudia Meyer, Amy Jankovsky, and Christopher Fulton

\section{PERFORIING ORGANIZATION NAME(S) AND ADDRESS(ES)}

8. Perforuing organization REPORT NUMBER

National Aeronautics and Space Administration

Lewis Research Center

Cleveland, Ohio 44135-3191

9. SPONSORING/MONTORING AGENCY NAME(S) AND ADDRESS(ES)

National Aeronautics and Space Administration

Washington, D.C. 20546-0001
10. SPONSORING/MONITORING AGENCY REPORT NUMBER

NASA TM-106234

AIAA-93-1779

\section{SUPPLEMENTARY NOTES}

Prepared for the 29th Joint Propulsion Conference and Exhibit, cosponsored by the AIAA, SAE, ASME, and ASEE, Monterey, California, June 28-30, 1993. William Maul and Claudia Meyer, Sverdrup Technology, Inc., Lewis Research Center Group, 2001 Aerospace Parkway, Brook Park, Ohio 44142; Amy Jankovsky, NASA Lewis Research Center, Cleveland, Ohio, and Christopher Fulton, Analex Corporation, 3001 Aerospace Parkway, Brook Park, Ohio 44142. Responsible person, William Maul, (216) 433-7496.

122 DISTRIBUTION/AVAILABILTYY STATEMENT

Unclassified - Unlimited

Subject Categories 15 and 63

\section{ABSTRACT (Max/mum 200 words)}

A diagnostic software package is currently being developed at NASA Lewis Research Center that utilizes qualitative model-based reasoning techniques. These techniques can provide diagnostic information about the operational condition of the modeled rocket engine system or subsystem. The diagnostic package combines a qualitative model solver with a constraint suspension algorithm. The constraint suspension algorithm directs the solver's operation to provide valuable fault isolation information about the modeled system. A qualitative model of the Space Shuttle Main Engine's oxidizer supply components was generated. A diagnostic application based on this qualitative model has been constructed to process four test cases: three numerical simulations and one actual test firing. The diagnostic tool's fault isolation output compared favorably with the input fault condition.

\section{SUBJECT TERMS}

Diagnostic reasoning; Qualitative model; Health monitoring

17. SECURTY CLASSIFICATION OF REPORT

Unclassified
18. SECURITY CLASSIFICATION OF THIS PAGE

Unclassified
19. SECUAITY CLASSIFICATION OF ABSTRACT Unclassified
15. NUMBER OF PAGES 14

16. PRICE CqgF

20. UIATATION OF ABSTRACT

Standard Form 298 (Rev. 2-89) Prescribed by ANSI Std. Z39-18 298-102 